\title{
ACTINOMICOSE MANDIBULAR EM OVINO: RELATO DE CASO
}

\author{
J.M.A.P. Antunes ${ }^{1}$, A.C.S. Almeida ${ }^{1}$, M.G. Ribeiro ${ }^{1}$, \\ R.L. Amorim ${ }^{2}$, C.A. Hussni ${ }^{3}$, F.J.P. Listoni ${ }^{1}$, J. Megid ${ }^{1}$
}

${ }^{1}$ Universidade Estadual Paulista, Faculdade de Medicina Veterinária e Zootecnia, Departamento de Higiene Veterinária e Saúde Pública, Distrito de Rubião Junior, s/no, CEP 18618-970, Botucatu, SP, Brasil. E-mail: joaomarceloantunes@live.com

\section{RESUMO}

O agente primário da actinomicose/osteomielite mandibular é o Actinomyces bovis que infecta principalmente ossos da cavidade oral de bovinos, acarretando prejuízos econômicos devido a perda de peso ocasionada pela dor à mastigação. $\mathrm{O}$ diagnóstico é comumente realizado por um bom exame clínico, radiográfico, bacterioscopia e cultivo microbiológico. Neste relato é apresentado o caso de um ovino com aumento localizado de mandíbula. O exame radiográfico demonstrou osteomielite. Amostras da lesão foram coletadas para realização de exame microbiológico e histopatológico. A histopatologia evidenciou lesão piogranulomatosa e na bacterioscopia foi demonstrado um agente Gram-positivo ramificado, filamentoso e catalase negativo. Os achados clínicos associados aos resultados dos exames complementares confirmaram a ocorrência incomum de infecção mandibular por A. bovis em um ovino.

PALAVRAS-CHAVE:Actinomyces bovis, actinomicose, osteomielite mandibular, mandíbula nodular.

\section{ABSTRACT}

JAW ACTINOMYCOSIS IN A SHEEP: CASE REPORT. The primary agent of actinomicosis/ mandibular osteomyelitis is Actinomyces bovis that infects mainly bones of the oral cavity of cattle, resulting in economic losses due to weight loss caused by pain on chewing. The diagnosis is usually made by a good clinical examination, radiographic, bacterioscopy and microbiological culture. This report describes the case of a sheep that had localized increase of the jaw, where the material from the lesion was collected for microbiological and histopathological diagnosis. Osteomyelitis was demonstrated by radiography. Piogranuloma was observed at the histophatology. Bacterioscopy evidenced a Gram-positive, branched, filamentous and catalase negative agent. The main clinical findings and diagnoses confirmed the occurrence of unusual jaw infection by A. bovis in a sheep.

KEY WORDS: Actinomyces bovis, actinomicosis, mandibular osteomyelitis, lumpy jaw.

A actinomicose/osteomielite mandibular, ou "mandíbula nodular", ou "lumpy jaw" é reconhecida como uma doença infecciosa de animais causada pelo Actinomyces bovis. A infecção é caracterizada por processos piogranulomatosos na cavidade bucal, de difícil resolução terapêutica, na qual a infecção ocorre provavelmente devido a lesões em mucosa oral, que permitem o agente se instalar nos tecidos e causar uma osteomielite localizada em mandíbula e/ou maxila (QuinN et al., 2005). Bacilos do gênero Actinomyces pertencem à microbiota da cavidade oral etratogastrintestinal de mamíferos e dehumanos. São micro-organismos anaeróbios, filamentosos, ramifi- cados, não formadores de esporos e de propriedades morfotintoriais Gram-positivas (RIET-CORREA et al., 2001). Em seres humanos o agente mais comumente implicado com infecções orais é o Actinomyces israelii (DíEZ et al., 2010). Em animais domésticos a doença ocorre com maior frequência em bovinos, bubalinose equinos, de diversas idades, enquanto que, em ovinos é considerada de ocorrência rara (RIET-CORREA et al., 2001; NAvarRe, 2004; AsaWI, 2009). A actinomicose mandibular também é descrita em ovinos silvestres, lhamas e alpacas (HoEFs; BunCH, 2001; NiEHAUS, 2009). Em ovinos silvestres é mais prevalente em fêmeas e nos machos pode comprometer o desenvolvimento

${ }^{2}$ Universidade Estadual Paulista, Faculdade de Medicina Veterinária e Zootecnia, Departamento de Clínica Veterinária, Botucatu, SP, Brasil.

${ }^{3}$ Universidade Estadual Paulista, Faculdade de Medicina Veterinária e Zootecnia, Departamento de Cirurgia e Anestesiologia Veterinária, Botucatu, SP, Brasil. 
doschifres (HoEFs; BunCH, 2001). A doença geralmente é secundária à infecções periodontais e às lesões na mucosa oral decorrentes dealimentaçãocom forragens grosseiras. Após a infecção gengival ou periodontal o micro-organismo penetra nos tecidos e ossos ocasionando osteomielite, que é predominantemente na região horizontal da mandíbula, determinando uma neoformação óssea nodular (RIET-CORREA et al., 2001). Inicialmente, não há drenagem espontânea da lesão. No entanto, com a cronificação do processo pode ocorrer formação de fístulas, com o envolvimento de raízes dentárias, que levam a dor à mastigação, com consequente diminuição do apetite e perda de peso (SмIтH, 2006). Os sinais clínicos se caracterizam pela presença de tumefação ou massa de consistência dura, localizada em região de dentes molares ou pré-molares, preferencialmente na mandíbula e ocasionalmente na maxila. A presença de pus amarelado com pequenos e duros grânulos de enxofre são visualizados principalmente nos casos em que há fistulização (QuinN et al., 2005). Dificuldade respiratória devido o envolvimento de ossos nasais pode ser o primeiro sinal clínico observado quando a maxila é afetada (NIEHAUS, 2009). As alterações macroscópicas são indicadas por uma osteomielite proliferativa que altera a conformação dos ossos da mandíbula, cau- sando danos aos dentes, com presença de tecidos de cicatrização abundantes e fístulas. Na histopatologia as alterações microscópicas predominantes são uma osteomielite piogranulomatosa, com proliferação de tecido fibroso e presença de rosetas no centro do piogranuloma, circundada por células inflamatórias (Quinn et al., 2005). O diagnóstico de rotina é baseado nos achados epidemiológicos, sinais clínicos eexames complementares, queincluem cultivo microbiológico, exame radiográfico, esfregaços corados pelo método de Gram e histopatologia (RIET-CorreA et al., 2001). A visualização de rosetas com clavas na histopatologia, somada ao seu isolamentoeachadosclínicos permitem confirmar o diagnóstico (NIEHAUS, 2009). Os principais diagnósticos diferenciais são: actinobacilose ou "língua de pau" causadas pelo Actinobacillus lignieressi, abcessos ocasionados por Arcanobacterium pyogenes, Staphylococcus spp., eNocardia spp. ecorpos estranhos na cavidade oral (RADOsTits et al., 2007). O controle da actinomicose é realizado evitando-se alimentos grosseiros. Animais que já possuem lesões devem ser isolados do rebanho e as instalações devem ser devidamente desinfetadas (SмIтH et al., 2006). O presente relato de caso descreve a ocorrência incomum deactinomicose emumovino, comênfase nos exames complementares de diagnóstico e achados clínicos.
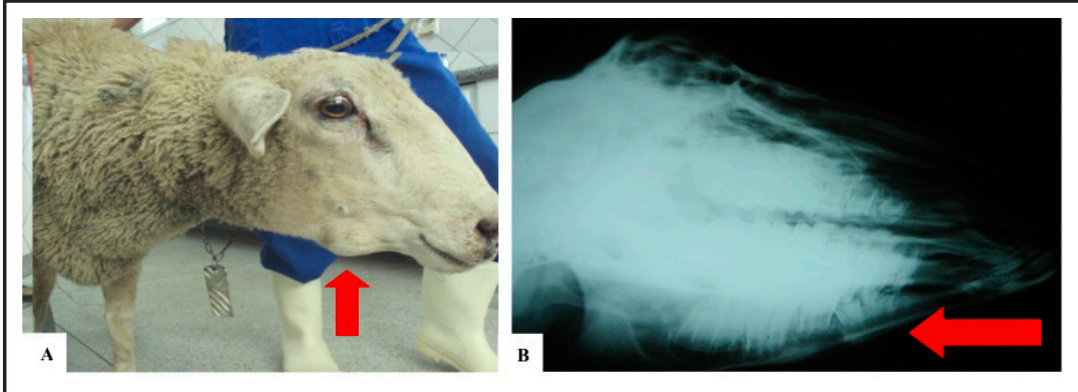

Fig. 1 - Actinomicose mandibular em ovino. $\mathrm{A}=$ Aumento de volume em terço médio do ramo horizontal de mandíbula direita (seta); $\mathrm{B}=$ Radiografia da mandíbula demostrandoárea
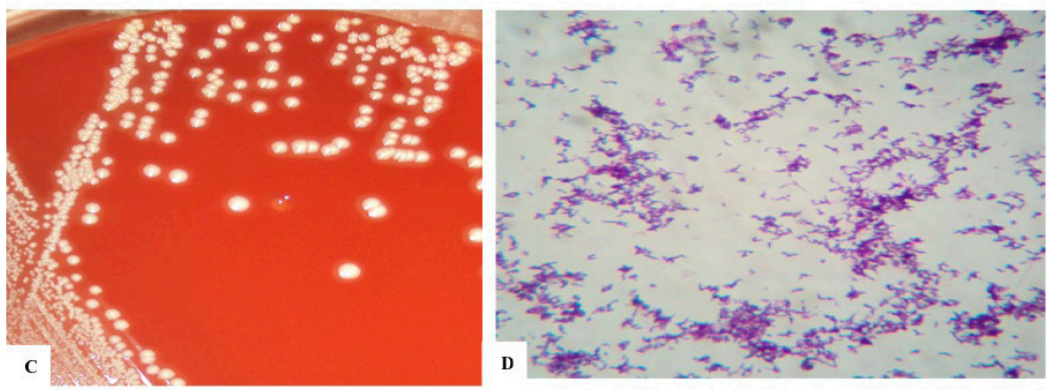
radioluscente compatível com perda óssea em região de dentes molares (seta), compatível com osteomiolite; $\mathrm{C}=$ Detalhe do isolamento de $A$. bovis mostrando colônias esbranquiçadas não hemolíticas, no meio de ágar sangue ovino, após 48 horas de cultivo; D = Bacilos Gram-positivos de aspecto filamentoso sugestivos de $A$. bovis na bacterioscopia do conteúdo purulento da lesão mandibular (Gram, 1000x); $\mathrm{E}=$ Área de neoformação e rarefação óssea na região dos dentes molares em terço médio do ramo horizontal de mandíbula direita; $F$ = Presença de necrosecaseosa circundada por cápsula e polimorfonucleares degenerados. 
O relato de caso foi projetado de acordo com as diretrizes atuais para o uso ético de animais na investigação da Comissão de Ética no Uso de Animais (CEUA, 13/10/2009) da UNESP, e de acordo com as leis brasileiras (24.645/1934 e 9.605/1998). Os experimentos foram conduzidos com a aprovação do ComitêdeÉtica da UNESP (Comitêde Ética protocolo 167/2008). Em um carneiro,SRD, de14meses deidade proveniente do Aprisco Experimental de Doenças Infecciosas da Faculdade de Medicina Veterinária e Zootecnia da UNESP, Botucatu, SP, foi observado aumento de volumenodular com localizaçãoe em terço médio do ramo horizontal de mandíbula direita (Fig. 1A). O carneiro se alimentava de ração comercial, feno e gramínea da espécie Brachiaria brizantha. Ao exame clínico o nódulo apresentou consistência firme à palpação, indolor, sem aumento de temperatura, alopecia e fístula. O nódulo media aproximadamente $5 \mathrm{~cm}$ de largura por $7 \mathrm{~cm}$ de comprimento. $\mathrm{O}$ animal apresentava normorexia, normodipisia e temperatura retal de $38,5^{\circ} \mathrm{C}$. Após o exame clínico, os procedimentos para o diagnóstico foram baseados na colheita de sangue para realização de hemograma, seguida de exame radiográfico da lesão e punção aspirativa com agulha fina da lesão nodular em mandíbula para o diagnóstico bacterioscópico e microbiológico (RIBEIRO et al., 2001). O cultivo microbiológico do material aspirado foi realizado em ágar sangue ovino (5\%) desfibrinado e ágar MacConkey, incubados em condições de aerobiose, anaerobiose e microaerofilia, a $37^{\circ} \mathrm{C}$, por até 5 dias. Do conteúdo purulento da lesão foi realizado esfregaço direto corado pelo método de Gram. A prova bioquímica da catalase também foi realizada (QuinN et al., 2005). Em virtude de A. bovis ocasionar a formação de um piogranuloma, de ser refratário à terapia convencional (CORRÊA; CORRÊA, 1992) e do risco de transmissão aos demais animais contactantes, o animal foi submetido à eutanásia. Um fragmento da lesão nodular do osso mandibular foi fixado em formalina $10 \%$ e encaminhado ao exame histopatológico com coloração de Hematoxilina \& Eosina (HE) (QuinN et al., 2005).

Nenhuma alteraçãofoi observada no hemograma. A Figura 1B demonstra a radiografia da mandíbula com área radioluscente compatível com perda óssea em região de dentes molares, sugerindo osteomiolite. Noesfregaço do material purulento foram observados bastonetes Gram-positivos filamentosos/ramificados (Fig. 1D), entretanto, não foram detectados os denominados "grânulos de enxofre", característicos da doença. Do cultivo microbiológico em condições de anaerobiose e microaerofilia em ágar sangue foram observadas, após 48 horas, colônias esbranquiçadas não hemolíticas, com $1 \mathrm{~mm}$ de diâmetro (Fig. 1C). O testebioquímico para catalasefoinegativo. Na necropsia foi observado aumento de volume de consistência dura em região de terço médio do ramo horizontal da mandíbula direita. Ao corte da lesão foi encontrada uma área de neoformação óssea na região dos dentes molares com área de rarefação óssea (Fig. 1E), sem comprometimento das demais estruturas ósseas adjacentes. Histologicamente, a lesão mandibular revelou ao centro a presença de pequenas colônias bacterianas, necrose caseosa e polimorfonucleares degenerados, circundado por cápsula fibrosa (Fig.1F). A caracterização morfotintorial, o exame histopatológico, o cultivo, os achados clínicos e de necropsia e bioquímica do microrganismo permitiram classificar o agente como A. bovis (QuinN et al., 2005).

A actinomicoseéconsiderada uma doença mandibular de animais domésticos e de espécies silvestres, ocasionalmente afetando os ossos da maxila, do palatino e dos turbinados (BARICHELlo et al., 1989). De acordo com QuinN et al. (2005), os espécimes adequados para o diagnóstico de actinomicose são amostras de exsudatos e de aspirados da lesão para bacterioscopia e cultivo. A confirmação do diagnóstico é realizada principalmente pela observação do aumento localizado em mandíbula e visualização de bactérias Gram-positivas filamentosas e ramificadas pela bacterioscopia (NIEHAUs, 2009). Em pequenos ruminantes a actinomicose é considerada uma afecção rara, visto que em animais de produção a doença é observada com maior frequência nos bovinos (RIET-Correa et al., 2001). A prevalência da actinomicose em ovinos é maior em espécies silvestres, variando de $0,4 \%$ a $29,3 \%$ (Hoefs; Bunch, 2001). A ocorrência da actinomicose em animais domésticos está intimamente relacionada à infecção de $A$. bovis por ferimentos nacavidade bucal, provocada comumente por forrageiras grosseiras ou pontiagudas, ou por invasão periodontal, particularmente no período de troca de dentes (RIET-CoRrEA et al., 2001). Em ovinos silvestres a infecção está associada a crescimento anormal dos dentes, forragens grosseiras, injúrias de brigas e infecção secundária por trauma oral (GLAZE et al., 1982; BARICHELLO et al., 1989). No presente relato, apesar da presença da lesão, o animal não apresentou dificuldades de alimentação. $\mathrm{O}$ animal relatado consumia alimentos de boa qualidade e não apresentava lesões periodontais aparentes ao exame bucal. No entanto, se encontrava em faixa etária de troca de dentições. Tal fato pode ter favorecido a invasão de $A$. bovis na região mandibular, já que a bactéria é encontrada com frequência na microbiota da cavidade oral de ruminantes domésticos (HoEFs; BunCH, 2001). Clinicamente, a actinomicose em animais de produção é caracterizada pela formação de lesões nodulares endurecidas, com ou sem fistulação, predominantemente na região de mandíbula e ocasionalmente, na maxila ou outras estruturas ósseas adjacentes (RIET-CoRrea et al., 2001). No presente relato de caso foi descrito uma única lesão na região do terço médio do ramo horizontal da mandíbula 
direita, com consistência endurecida e sem formação de fístulas. A citologia aspirativa seguida de bacterioscopia é utilizada na rotina de diagnóstico de outras doenças em ovinos e caprinos - como nas infecções por Corynebacterium pseudotuberculosis, possibilitando diagnóstico acurado, rápido, de simples execução e de baixo custo (Ribeiro et al., 2001). Apesar da visualização de bacilos Gram-positivos de aspecto filamentoso na bacterioscopia, faz-se necessário no diagnóstico definitivo o isolamento do microrganismo e caracterização bioquímica, em virtude da similaridade da lesão bucal da actinomicose com a actinobacilose e nocardiose. No entanto, o gênero Nocardia é isolado em aerobiose, apesar de também seapresentar como bactérias Gram-positivas filamentosas (RibeIro et al., 2008). Em contraste, o gênero Actinobacillus se apresenta como bacilos Gram-negativos e desenvolve lesões predominantemente na língua dos animais (QuinN et al., 1994; RADOSTITS et al., 2007). Em carneiros silvestres a osteomielite é relatada devido infecção por Arcanobacterium pyogenes, Fusobacterium necrophorum, Streptococcus spp. e Streptococcus spp. (NeILAND, 1972; HeImer et al., 1982; GLAZE et al.,1982). Geralmente, estas enfermidades de diagnóstico diferencial comprometem os linfonodos de cabeça e pescoço (RADOsTITs et al., 2007). No presente estudo, a única alteração clínica evidenciada foi o nódulo em mandíbula. Macroscopicamente a actinomicose em animais de produção se caracteriza por osteomielite proliferativa com focos purulentos. Histologicamente se observa osteomielite piogranulomatosa, contendo no centro o microrganismo circundado por macrófagos modulados em células epitelioides - em estruturas similares a "clavas" circundado por contingente diverso de outras células como linfócitos, neutrófilos e plasmócitos, envolto por cápsula fibrosa (CORRÊA; CORRÊA, 1992). No animal relatado, o exame histológico da lesão mandibular foi caracterizada como piogranulomatosa. Não foram visualizadas clavas, entretanto, para QuiNN et al. (2005), na actinomicose, a visualização de clavas pode ou não estar presente e sua ausência pode estar associada a regressão da lesão. Ademais, em virtude dos riscos de propagação da doença entre os demais animais do plantel e da baixa eficácia terapêutica da doença utilizando antimicrobianos convencionais, o animal foi eutanasiado. A reduzida eficiência terapêutica na actinomicoseéjustificada pela dificuldade dos antimicrobianos em atingirem concentrações terapêuticas no interior do foco piogranulomatoso, recomendando-se a eutanásia (CORRÊA; CORRÊA, 1992; Riet-Correa et al., 2001). A gravidade da lesão imposta pelo micro-organismo na cavidade bucal do ovino e a opção pelo não tratamento do animal, reforçam o prognóstico reservado a desfavorável na actinomicose em animais de produção. Em virtude da capacidade de disseminação do micro-organismo para outros animais, recomenda-se que na suspeita de actinomicose os animais sejam isolados até que se proceda ao diagnóstico e/ou opção pelo tratamento, evitando a propagação da doença no plantel (SMITH et al., 2006). De acordo com BARRICHELO et al. (1989) e GLAzE et al. (1982) a actinomicose em ovinos silvestres pode causar a morte do animal por desnutrição e fome, diminuindo a expectativa de vida dos animais. Na bacterioscopia, após a citologia aspirativa por agulha fina, houve a visualização do agente Gram-positivo filamentoso-ramificado e na histopatologia corada por HE foi descrito a formação de um piogranuloma que, somado ao isolamento no ágar sangue, permitiu junto com os achados clínicos e de diagnóstico diferencial, a confirmação de $A$. bovis. Atualmente existem informações suficientes que a actinomicose compromete a produção em bovinos (CORRÊA; CorrêA, 1992; RIET-Correa et al., 2001), o que, podemos assumir que os efeitos negativos da actinomicose também comprometem a produtividade, levando a um impacto adverso na criação de ovinos. Apesar da baixa prevalência da actinomicose em carneiros e da escassa literatura atualizada, faz-se necessário a educação continuada desta enfermidade.

\section{REFERÊNCIAS}

ASAWI, O.I. A study on the pathological lesions of oviducts of buffaloes diagnosed at postmortem. Veterinary Research Communications, v.33, p.77-85, 2009.

BARICHELLO, N.; CAREY, J.; HOEFS, M.; HOEFS, H. Lumpy jaw in thinhorn sheep in the Yukon. Yukon: Yukon Department of Renewable Resources, Whitehorse, 1989, 20p.

CORRÊA, W.M.; CORRÊA, C.N.M. (Ed.). Enfermidades infecciosas dos animais domésticos. São Paulo: Medsi, 1992. 843p.

DÍEZ, M.D.S.; ASPAS, A.M.; ARJONA, M.M.O.; TINOCO, E.L. Actinomicosis. Medicine, v.10, n.53, p.35523557,2010

GLAZE, R.; HOEFS, M.; BUNCHA, T.D. Aberrations of the tooth arcade and mandible in Dall's sheep from southwestern Yukon. Journal of Wildlife Diseases, v.18, p.305-309, 1982.

HEIMER, W.E.; ZARNKE, R.L.; PRESTON, D.J. Disease surveys in Dall's sheep in Alaska. Biennial Symposium of the Northern Wild Sheep and Goat Council, v.3, p.188-197, 1982.

HOEFS, M.; BUNCH, T.D. Lumpy jaw in wild sheep and its evolutionary implications. Journal of Wildlife Diseases, v.31, n.1, p.39-48, 2001. 
NAVARRE, C.B. Enfermidades da Boca e do Esôfago - Actinomicose. In: (Ed.). Clínica de ovinos e caprinos. São Paulo: Roca, 2004. 499p.

NEILAND, K.A. Sheep Disease Studies. Juneau: Alaska Department of Fish and Game Project, 1972. 32p.

NIEHAUS, A. Dental disease in llamas and alpacas. Veterinary Clinics of North America: Food Animal Practice, v.25, p.281-293, 2009.

QUINN, P.J.; CARTER, M.F.; MARKEY, B.K.; CARTER, G.R. Clinical veterinary microbiology. Brasil: ArtMed, 1994. 512p.

QUINN, P.J.; MARKEY, B.K; CARTER, M.E.; DONNELLY, W.J.; LEONARD, F.C. Actinomicetos. In: QUINN, P.J.; MARKEY, B.K; CARTER, M.E.; DONNELLY, W.J.; LEONARD, F.C. (Ed.). Microbiologia veterinária e doenças infecciosas. Porto Alegre: Artmed, 2005. p.74-82.

RADOSTITS, O.M.; GAY, C.C.; BLOOD, D.C.;

HINCHCLIFF, K.W. Clínica veterinária: um tratado de doenças dos bovinos, ovinos, suínos, caprinos e eqüinos. 8.ed. Rio de Janeiro: Guanabara Koogan, 2007. 1737p.
RIBEIRO, M.G.; DIAS JÚNIOR, J.G.; PAES, A.C.; BARBOSA, P.G.; NARDI JÚNIOR, G.; LISTONI, F.J.P. Punção aspirativa com agulha fina no diagnóstico de Corynebacterium pseudotuberculosis na linfadenite caseosa caprina. Arquivos do Instituto Biológico, São Paulo, v.68, n.1, p.23-28, 2001

RIBEIRO, M.G.; SALERNO, T.; MATTOS-GUARALDI, A.L.; CAMELLO, T.C.F.; LANGONI, H.; SIQUEIRA, A.K.; PAES, A.C.; FERNANDES, M.C.; LARA, G.H.B. Nocardiosis an overview and additional report of 28 cases in cattle and dogs. Revista do Instituto de Medicina Tropical de São Paulo, v.3, p.177-185, 2008.

RIET-CORREA, F. Actinomicose. In: (Ed.). Doenças de ruminantes e eqüinos. 2.ed. São Paulo: Varela, 2001. v.1, 423p.

SMITH, B.P. Medicina interna de grandes animais. 3.ed. São Paulo: Manole, 2006. 1728p.

Recebido em $8 / 4 / 11$

Aceito em 21/5/45 